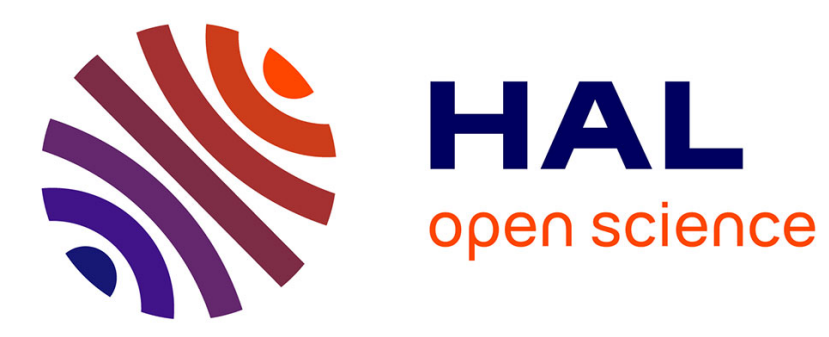

\title{
Detailed Characterization of Monoclonal Antibody Receptor Interaction Using Affinity Liquid Chromatography Hyphenated to Native Mass Spectrometry
}

Rabah Gahoual, Anna-Katharina Heidenreich, Govert W Somsen, Patrick Bulau, Dietmar Reusch, Manfred Wuhrer, Markus Haberger

\section{To cite this version:}

Rabah Gahoual, Anna-Katharina Heidenreich, Govert W Somsen, Patrick Bulau, Dietmar Reusch, et al.. Detailed Characterization of Monoclonal Antibody Receptor Interaction Using Affinity Liquid Chromatography Hyphenated to Native Mass Spectrometry. Analytical Chemistry, 2017, 89 (10), pp.5404-5412. 10.1021/acs.analchem.7b00211 . hal-03206846

\section{HAL Id: hal-03206846 https://hal.science/hal-03206846}

Submitted on 23 Apr 2021

HAL is a multi-disciplinary open access archive for the deposit and dissemination of scientific research documents, whether they are published or not. The documents may come from teaching and research institutions in France or abroad, or from public or private research centers.
L'archive ouverte pluridisciplinaire HAL, est destinée au dépôt et à la diffusion de documents scientifiques de niveau recherche, publiés ou non, émanant des établissements d'enseignement et de recherche français ou étrangers, des laboratoires publics ou privés. 


\title{
Detailed Characterization of Monoclonal Antibody Recep- tor Interaction Using Affinity Liquid Chromatography Hy- phenated to Native Mass Spectrometry
}

\author{
Rabah Gahoual ${ }^{1}$, Anna-Katharina Heidenreich ${ }^{2}$, Govert W. Somsen ${ }^{1}$, Patrick Bulau ${ }^{2}$, Dietmar Re- \\ usch $^{2}$, Manfred Wuhrer ${ }^{1,3}$, Markus Haberger ${ }^{2}$ \\ ${ }^{1}$ Division of Bioanalytical Chemistry, Amsterdam Institute for Molecules, Medicines and Systems, Department of \\ Chemistry and Pharmaceutical Sciences, Faculty of Science, Vrije Universiteit, De Boelelaan 1085, 1081 HVAmster- \\ dam, The Netherlands \\ ${ }^{2}$ Pharma Technical Development Penzberg, Roche Diagnostics GmbH, Penzberg 82377, Germany \\ ${ }^{3}$ Center for Proteomics and Metabolomics, Leiden University Medical Center, 2333 ZA Leiden, The Netherlands
}

\section{Corresponding author: \\ E-mail: r.gahoual@vu.nl. \\ ORCID}

Rabah Gahoual: 0000-0001-8459-3138 
ABSTRACT: We report on the online coupling of FcRn affinity liquid chromatography (LC) with electrospray ionization mass spectrometry (ESI-MS) in native conditions to study the influence of modifications on the interaction of recombinant mAbs with the immobilized FcRn receptor domain. The analysis conditions were designed to fit the requirements of both affinity LC and ESI-MS. The mobile phase composition was optimized to maintain the proteins studied in native conditions and enable sharp $\mathrm{pH}$ changes in order to mimic properly IgGs Fc domain/FcRn receptor interaction. Mobile phase components needed to be sufficiently volatile to achieve native MS analysis. MS data demonstrated the conservation of the pseudo native form of IgGs and allowed identification of the separated variants. Native FcRn affinity LC-ESI-MS was performed on a therapeutic mAb undergoing various oxidation stress. Native MS detection was used to determine the sample oxidation level. Lower retention was observed for mAbs oxidized variants compared to their intact counterparts indicating decreased affinities for the receptor. This methodology proved to be suitable to identify and quantify post-translational modifications at native protein level in order to correlate their influence on the binding to the FcRn receptor. Native FcRn affinity LC-ESIMS can tremendously reduce the time required to assess the biological relevance of the IgG microheterogeneities thus providing valuable information for biopharmaceutical research and development. 


\section{INTRODUCTION}

Monoclonal antibodies (mAbs) and their related formats are successful drugs in various therapeutic fields, including oncology and autoimmunity. The success of mAbs as therapeutic proteins can in part be attributed to their intrinsic properties such as specificity for the targeted antigen and pharmacokinetics/pharmacodynamics (PK/PD) properties favorable for therapeutic purpose. This category of therapeutic agents is derived from immunoglobulin $G$ (IgG) and includes various formats such as mAbs, antibody fragments (fusion protein), antibody-drug conjugates, bispecific antibodies, or glycoengineered antibodies. ${ }^{1} \mathrm{mAbs}$ are complex glycoproteins potentially affected by a wide range of microheterogeneities resulting from chemical or enzymatic modifications. ${ }^{2}$ To address the complexity resulting from this profusion of posttranslational modifications (PTMs), intensive research has been conducted in order to provide analytical methods that deliver detailed characterization of the various aspects of mAb structure and function. Indeed, mass spectrometry (MS) has progressively become an essential technique in mAbs characterization. ${ }^{3-5}$ Electrospray (ESI)-MS analysis performed in pseudonative conditions (native MS) enables one to maintain the protein tertiary and quaternary structure in the gas phase. ${ }^{6,7}$ Structural characterization of mAbs is often performed on the peptide level, which requires extensive sample treatment potentially introducing modifications and artifacts. ${ }^{8}$ In contrast, native MS workflows often succeed to minimize sample preparation and largely preserve the structure of the protein analytes. ${ }^{9,10}$ Therefore, it is extensively used to investigate higher-order structures of mAbs and their impact on the biological activity of the protein. ${ }^{11,12} \mathrm{MS}$ commonly benefits from hyphenation with chromatographic or electrophoretic separation techniques. ${ }^{13,14}$ Indeed, the ability to separate mAbs variants and to transfer them progressively to the MS source allows one to improve significantly the sensitivity, dynamic range, and, therefore, the detection of low-abundance variants by limiting competition effects during the ionization. Currently, some limitations observed for native MS experiments originate from the restrictions these conditions lay on the chromatographic separation, which may be particularly severe for complex mixtures. The analysis of complex mixtures by native MS remains a major challenge which is required to be addressed in order to demonstrate the complete potential of the technique.

Affinity liquid chromatography (affinity LC) is one of the separation techniques routinely used for the purification of 
recombinant IgGs. Currently protein A and protein G affinity LC are commonly applied because of their excellent specificity enabling isolation of mAbs even from complex mixtures on a preparative scale. ${ }^{15,16}$ Recently, affinity LC was described using an analytical stationary phase composed of immobilized neonatal FcRn receptors ${ }^{17}$ for the investigation of methionine oxidation. ${ }^{18}$ The FcRn receptor interacts with the $\mathrm{CH} 2-\mathrm{CH} 3$ hinge region of the crystallizable fragment $(\mathrm{Fc})$ of IgGs in a pH-dependent manner. The FcRn receptor- $\mathrm{IgG} F \mathrm{Fc}$ fragment interaction is involved in crucial in vivo processes, such as the transfer of antibodies from the mother to the fetus and the recycling of antibodies after endocytosis. ${ }^{19,20}$ It is responsible for the homeostasis of IgG in blood and contributes to the extended plasma halflife of IgGs compared to other plasma proteins..$^{21,22}$

In the present work, we developed an analytical method using online FcRn affinity LC-ESI-MS for the characterization of mAbs in native conditions. FcRn affinity LC conditions were designed to be fully compatible with native ESIMS in order to enable online coupling. A therapeutic mAb exposed to different oxidative stress conditions was studied using the developed method. Native FcRn affinity LC-ESI-MS provided separation of mAb variants indicating significantly different affinities. Identifications based on native MS data demonstrated the correlation of affinity changes with the occurrence of methionine oxidation.

\section{EXPERIMENTAL SECTION}

Chemicals used were of analytical grade or high-purity grade and purchased from Sigma-Aldrich (St. Louis, MO). Ultrapure water used to prepare buffers and sample solutions was obtained using a Milli-Q reference A+ water purification system purchased from Merck Millipore (Billerica, MA). The recombinant IgG1 antibody mAb1 was expressed in a glycoengineered Chinese hamster ovary (CHO) cell system ${ }^{23}$ at Roche Diagnostics (Penzberg, Germany) using conventional culture and purification technologies. mAb1 was formulated at a concentration of $15 \mathrm{mg} / \mathrm{mL}$ in an Lhistidine monohydrochloride (His-HCl) buffer system (20 mM His-HCl, $100 \mathrm{mM} \mathrm{NaCl}, \mathrm{pH}$ 6.0). The mAb1 formulation was subject to oxidative stress by incubation with hydrogen peroxide in order to qualify the system. The reference material and stressed samples of mAb2 were provided by Roche Diagnostics (Penzberg, Germany). The recombinant IgG is referred as mAb3, a triple A mutant (I266A, H329A, H466A) of an IgG1 antibody with abrogated FcRn binding capacity that was produced using a knob-into-hole technology and formulated at a concentration of $34 \mathrm{mg} / \mathrm{mL}$ 
in L-histidine monohydrochloride (His- $\mathrm{HCl}$ ) buffer system. ${ }^{24,25} \mathrm{mAb} 3$ is corresponding to the marketed formulation approved by the FDA/EMA and provided internally. Proteomics grade trypsin was provided by Roche Diagnostics (Mannheim, Germany).

Monoclonal Antibodies Deglycosylation. The mAbs samples deglycosylation was realized using recombinant Nglycosidase F (PNGase F) purchased from Roche Applied Science (Mannheim, Germany). The sample was adjusted to a concentration of $0.5 \mathrm{mg} / \mathrm{mL}$, then 16 units of PNGase $\mathrm{F}$ was added and the mixture was incubated overnight at 37 ${ }^{\circ} \mathrm{C}$. After PNGase F treatment, the sample buffer was exchanged into the composition of the FcRn affinity LC mobile phase (starting conditions) using $30 \mathrm{kDa}$ MWCO Amicon-Ultra $0.5 \mathrm{~mL}$ spin filter columns (Merck Millipore, Molsheim, France).

Monoclonal Antibodies Oxidative Stress Conditions. Oxidative stress was performed by mixing mAb2 sample with hydrogen peroxide $(\mathrm{H} 2 \mathrm{O} 2)$ at different concentrations ranging from $0.003 \%$ to $0.05 \%(\mathrm{v} / \mathrm{v})$. Mixtures were left at room temperature for $24 \mathrm{~h}$. H2O2 was removed using an NAPTM-5 gel filtration column. Stressed samples were kept at -18 ${ }^{\circ} \mathrm{C}$ until analysis. Samples were diluted to the desired concentration and split in two parts for peptide mapping experiments and FcRn affinity LC-ESI-MS experiments.

Peptide Mapping Using Tryptic Digestion. mAb2 stressed samples were first denatured by dilution in $0.2 \mathrm{M}$ His-HCl, $8 \mathrm{M}$ guanidine-HCl (pH 6.0). Dithiothreitol (DTT) was added to the sample to a final concentration of 20 $\mu \mathrm{M}$ followed by incubation at $50{ }^{\circ} \mathrm{C}$ for $1 \mathrm{~h}$. The chaotropic buffer solution was exchanged to the digestion buffer of $0.2 \mathrm{M}$ His- $\mathrm{HCl}(\mathrm{pH}$ 6.0) using an NAPTM-5 gel filtration column. Gel filtration eluates were mixed with $10 \mu \mathrm{L}$ of trypsin diluted at a concentration of $0.25 \mathrm{mg} / \mathrm{mL}$ in $10 \mathrm{mM} \mathrm{HCl}$. Samples were incubated at $37{ }^{\circ} \mathrm{C}$ for $18 \mathrm{~h}$.

Peptide Digest Analysis by Liquid Chromatography-Mass Spectrometry. Tryptic peptide mixtures were separated by reversed-phase liquid chromatography (RPLC) on a Waters BEH C18 $1.7 \mu \mathrm{m}, 2.1 \mathrm{~mm} \times 150 \mathrm{~mm}$ column using an ultrahigh-performance liquid chromatography system (Waters ACQUITY UPLC; ACQUITY column manager type ACQCM 1.40, binary solvent manager type ACQ-BSM 1.65, sample manager type ACQ-SM 1.65; Manchester, U.K.). The mobile phases were composed of $0.1 \%$ formic acid (FA) in water (mobile phase A) and $0.1 \%$ FA in acetonitrile (mobile phase B). Peptides separation was carried out using a gradient from $1 \%$ to $35 \%$ B in 45 min and from $35 \%$ to 
$80 \% \mathrm{~B}$ in $3 \mathrm{~min}$ at a flow rate of $300 \mu \mathrm{L} / \mathrm{min}$ and column temperature of $65^{\circ} \mathrm{C}$. Amounts of $10 \mu \mathrm{L}(3.5 \mu \mathrm{g})$ of the samples were injected and analyzed online with a Synapt G2 mass spectrometer (Waters, U.K.). Data acquisition was controlled by MassLynx software (Waters).

Data Analysis for the Quantification of Met Oxidation at the Peptide Level. MassLynx raw data were converted and imported into GRAMS AI software (Thermo Fisher Scientific, Dreieich, Germany). For the quantification, specific ion current (SIC) chromatograms of peptides of interest were generated on the basis of their monoisotopic mass and all detected charge states using MassMap software (MassMap GmbH \& Co. KG, Wolfratshausen, Germany) installed on a GRAMS AI workstation. Relative amounts of Met oxidation were calculated by manual integration of modified and unmodified peptides.

Affinity Column Preparation. The preparation of the FcRn affinity column was described previously.17 Briefly, FcRn/ $\beta 2$-microglobulin in $5 \mathrm{~mL}$ of $20 \mathrm{mM}$ sodium citrate buffer, $\mathrm{pH} 5.5$ containing $150 \mathrm{mM} \mathrm{KCl,} 250 \mu \mathrm{L}$ of $\mathrm{PBS}$, and 1 tablet of complete protease inhibitor (cOmplete ULTRA Tablets, Roche Diagnostics) were added, and the sample was biotinylated using a biotinylation Bulk BIRA kit following the manufacturer's instructions (Avidity LLC, Aurora, $\mathrm{CO}$ ). The modified protein was dialyzed against $20 \mathrm{mM}$ sodium phosphate buffer comprising $150 \mathrm{mM} \mathrm{NaCl}, \mathrm{pH} 7.5$ at $4{ }^{\circ} \mathrm{C}$ overnight to remove excess of biotin. For coupling to streptavidin Sepharose, $1 \mathrm{~g}$ of streptavidin Sepharose (GE Healthcare) was added to the biotinylated receptor and dialyzed receptor and incubated for $2 \mathrm{~h}$ with shaking. The receptor-derivatized Sepharose was filled in a $1 \mathrm{~mL}$ XK column (GE Healthcare), and the FcRn column was then equilibrated with $20 \mathrm{mM}$ 2-(N-morpholine)-ethanesulfonic acid (MES) buffer containing $150 \mathrm{mM} \mathrm{NaCl,} \mathrm{pH} 5.5$.

FcRn Affinity Liquid Chromatography. When necessary, mAbs samples were diluted to the desired concentration using $20 \mathrm{mM}$ MES buffer ( $\mathrm{pH}$ 5.5). From 45 up to $60 \mu \mathrm{g}$ of protein was injected onto the FcRn column using an Ultimate3000 UHPLC system (Thermo-Fischer, Manchester, U.K.) using a flow rate of $500 \mu \mathrm{L} / \mathrm{min}$. Mobile phases used for the chromatography contained $150 \mathrm{mM}$ ammonium acetate, pH 5.5 (mobile phase A) and $150 \mathrm{mM}$ ammonium acetate, $\mathrm{pH} 8.8$ (mobile phase B) adjusted with glacial acetic acid and ammonia, respectively. Following sample injection, the column was equilibrated for $10 \mathrm{~min}$ with $20 \% \mathrm{~B}$. The gradient required to study the interactions between the $\mathrm{mAb}$ and the FcRn receptor was ranging from $20 \%$ to $45 \% \mathrm{~B}$ in $25 \mathrm{~min}$ and from $45 \%$ to $60 \% \mathrm{~B}$ in $30 \mathrm{~min}$. In order 
to ensure complete elution of the sample and reconditioning, the column was flushed with $80 \%$ B for 5 min followed with $20 \%$ B for 10 min.

Native FcRn Liquid Chromatography-Electrospray Ionization Mass Spectrometry. Native FcRn LC-ESI-MS experiments were performed by direct hyphenation with a Maxis HD mass spectrometer (Bruker Daltonics, Bremen, Germany). For these experiments, mobile phase flow transferred to the MS was reduced using a flow splitter (1:50) prior to introduction to the ESI source, in order to have a constant flow rate of $10 \mu \mathrm{L} / \mathrm{min}$ directed to the MS. MS parameters were optimized so that ions of interest could be properly transferred to the time-of-flight (TOF) analyzer while avoiding fragmentation. ESI source parameters were set as follows: ESI voltage, $-4.3 \mathrm{kV}$; nebulizing gas pressure, 0.6 bar. Dry gas was set to $4.2 \mathrm{~L} / \mathrm{min}$ and source temperature to $140{ }^{\circ} \mathrm{C}$. Ion funnels were set at values of $400 \mathrm{~V}$ per parts (Vpp). Mass-to-charge ratio (m/z) recorded was ranging from 2000 to 9000 using a frequency of $0.5 \mathrm{~Hz}$. DataAnalysis software (Bruker Daltonics) was used for native MS data treatment.

\section{RESULTS AND DISCUSSION}

Online Native FcRn Affinity LC-ESI-MS Method Development. Even though affinity LC is well-established for the purification of recombinant IgGs, the implementation of receptors as stationary phase components has only been recently described for the FcRn receptor.17 At acidic condition, the Fc fragment of IgGs is binding to the FcRn receptor, whereas at physiological $\mathrm{pH}$ the interaction is nearly abolished, provoking the release of the antibody. The IgG $\mathrm{Fc}-\mathrm{FcRn}$ interaction is responsible for the extended serum half-life of IgG compared to other types of serum proteins. ${ }^{21}$ Indeed, some characteristics crucial for the use of mAbs as therapeutic treatment are conditioned by protein-protein interactions. ${ }^{26,27}$ The ability to study the influence of post-translational modifications of mAbs on FcRn binding can provide essential information during $\mathrm{mAb}$ research and development due to the established role of the FcRn interaction in protein clearance..$^{28}$ 


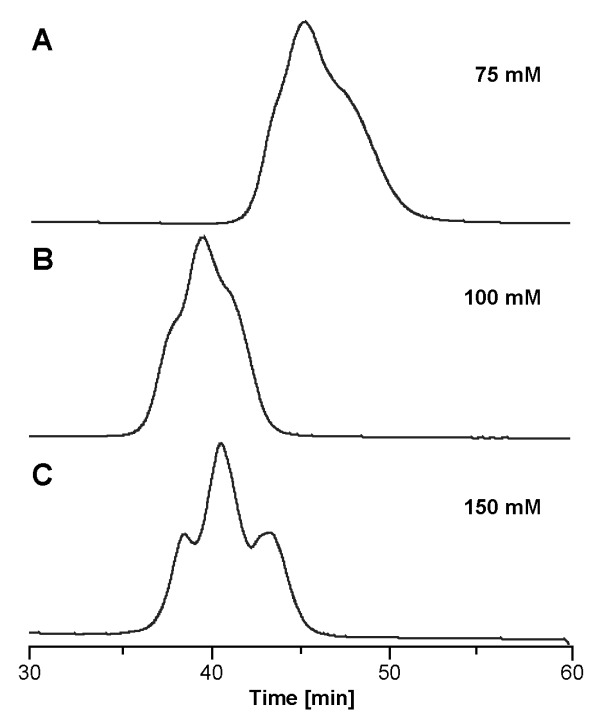

Figure 1. Total ion chromatogram (TIC) recorded during analysis of oxidized $\mathrm{mAb} 1$ by native FcRn LC-ESI-MS with a $\mathrm{pH}$ gradient from 5.5 to 8.5 using (A) $75 \mathrm{mM}$ ammonium acetate, (B) $100 \mathrm{mM}$ ammonium acetate, and (C) 150 $\mathrm{mM}$ ammonium acetate.

In order to achieve online FcRn affinity LC-ESI-MS, the composition of the mobile phase had to be thoroughly optimized to provide effective retention at acidic $\mathrm{pH}$ via interactions with receptors immobilized on the stationary phase and a complete release at physiological $\mathrm{pH}$. Furthermore, the mobile phase was required to be compatible with native MS experiments, meaning it had to maintain proteins in near-native state and be volatile to allow the generation of protonated species during the ESI process. ${ }^{29}$ Ammonium acetate was investigated as the buffering component of the mobile phase. Oxidized reference material of a recombinant IgG1 (mAb1), already used for the development of a FcRn affinity LC with UV absorbance detection in a previous study, was chosen for the optimization of the FcRn affinity LC-ESI-MS method. ${ }^{18}$ Initially, oxidized mAb1 (cf. the Experimental Section) was analyzed with different mobile phase compositions ranging from 75 up to $200 \mathrm{mM}$ ammonium acetate. A pH gradient was applied using a mixture of solutions of ammonium acetate of pH 5.5 and 8.5 as eluents. As emphasized in Figure 1A, the use of $75 \mathrm{mM}$ ammonium acetate enabled the complete retention of the injected sample; however, separation of oxidation variants was only partial and further improvements were needed. By increasing the concentration to $100 \mathrm{mM}$, retention times of the variants were reduced, whereas no beneficial effect on separation was noticed (Figure 1B). When the concentration of ammonium acetate was further increased to $150 \mathrm{mM}$, the detection window remained between 36 and 45 min, whereas the separation of mAb1 oxidation variants with different affinities with the FcRn receptor was significantly improved 
(Figure 1C). Above $150 \mathrm{mM}$ ammonium acetate concentration, the MS protein signal started to diminish due to excessive ion suppression effects (data not shown) ${ }^{30}$ In order to appreciate the efficiency of the separation achieved with a mobile phase composed of $150 \mathrm{mM}$ ammonium acetate, mAb1 was also analyzed using mobile phases composed of MES and Tris- $\mathrm{HCl}$ buffers with the same stationary phase. ${ }^{18}$ Results according to Figure S-2 demonstrated comparable separation indicating the conditions optimized for native MS analysis did not involve a loss of chromatographic resolution.

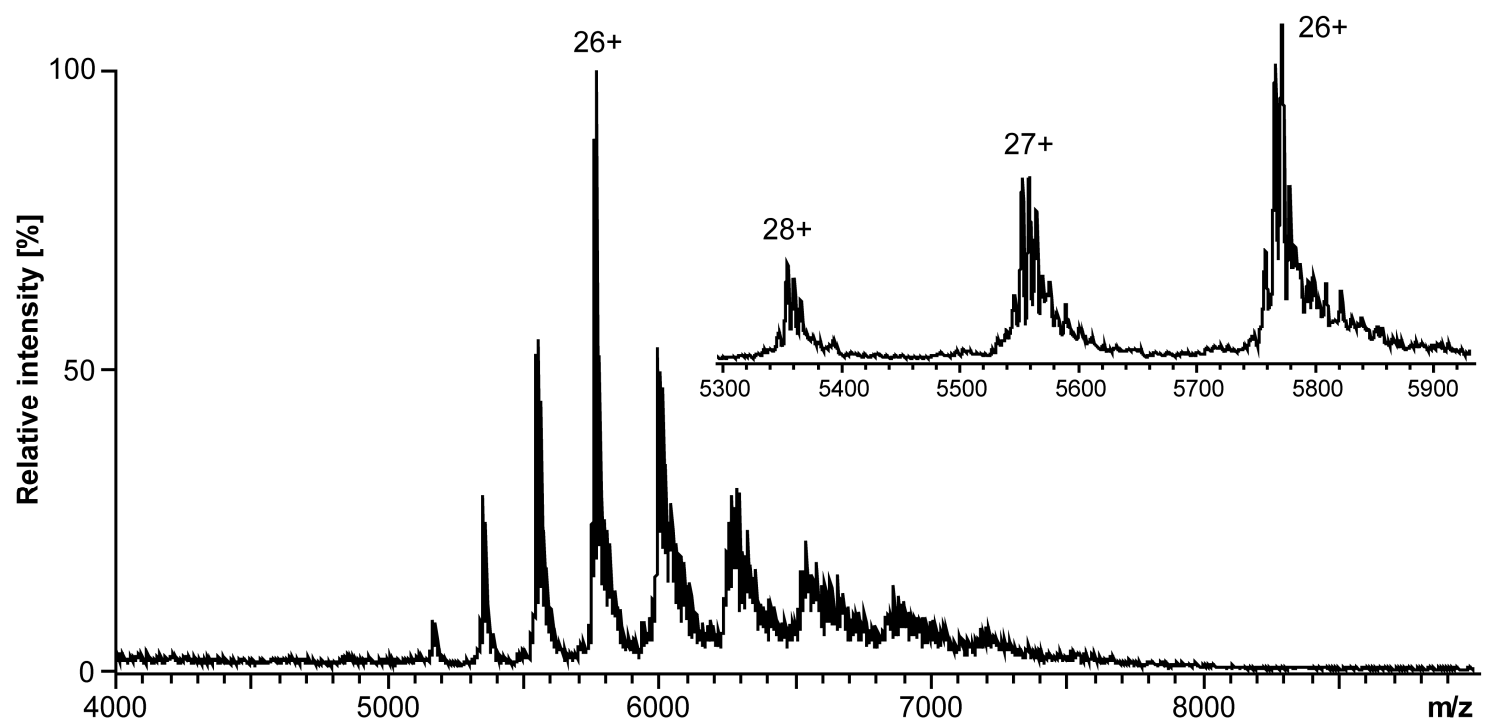

Figure 2. Mass spectrum of the second peak (39.1-41.4 min, Figure 1C) recorded during analysis of oxidized mAb1 by native FcRn LC-ESI-MS. The inset shows a zoom of the 5300-5940 m/z range.

Table 1. Protein Variants Assigned after Analysis of mAb1 by Native FcRn Affinity LC-ESI-MS ${ }^{a}$

\begin{tabular}{|c|c|c|c|c|c|}
\hline elution time (min) & glycoform & charge states & theor mass (Da) & no. of oxidations & exptl mass (Da) \\
\hline $35.5-38.9$ & H3N5/H3N4 & $22-29$ & 149713 & 2 & 149710 \\
\hline & H3N5/H3N5 & & 149916 & 2 & 149923 \\
\hline & H3N5/H4N5 & & 150078 & 2 & 150084 \\
\hline & H3N5F/H4N5 & & 150224 & 2 & 150223 \\
\hline H3)1-41.4 & H3N5/H3N4 & $22-29$ & 149697 & 1 & 149698 \\
\hline & H3N5/H3N5 & & 149900 & 1 & 149900 \\
\hline & H3N5/H4N5 & & 150062 & 1 & 150063 \\
\hline & H3N5F/H4N5 & & 150208 & 1 & 150211 \\
\hline & H3N5/H3N4 & $22-29$ & 149681 & 0 & 149677 \\
\hline & H3N5/H3N5 & & 149884 & 0 & 149889 \\
\hline & H3N5/H4N5 & & 150046 & 0 & 150053 \\
\hline & H3N5F/H4N5 & & 150192 & 0 & 150199 \\
\hline
\end{tabular}

${ }^{\mathrm{a}} \mathrm{H}$, hexose; N, N-acetylhexosamine; F, deoxyhexose (fucose). 
For FcRn affinity LC-ESI-MS analysis of oxidized mAb1, signals were detected in the m/z range of 5100-7000, exhibiting charge states ranging from $22+$ up to $30+$ (Figure 2). Conventional native MS analysis, using direct infusion of the sample, showed similar charge state distributions (data not shown) as obtained with FcRn affinity LC-ESI-MS experiments demonstrating the native form of the protein is maintained during the FcRn affinity separation and subsequent transfer to the gas phase. ${ }^{31} \mathrm{MS}$ data (inset Figure 2) showed a mass resolution allowing the assignment of the four major glycoforms of mAb1 (Table 1). The effect of the amount of mAb injected on MS resolution and signal intensity was also optimized. An injected quantity of $60 \mu \mathrm{g}$ of total protein was found to represent the best compromise between separation and detection sensitivity. Due to the mobile phase splitting only $1.2 \mu \mathrm{g}$ of the analyte was actually transferred to the MS for identification. Native MS data permitted assignment of oxidized mAb1 variants separated by FcRn affinity LC. As summarized in Table 1, the oxidized mAb1 variants identified in the last eluting peak (42.0-45.5 $\mathrm{min}$ ) are corresponding to the four major glycoforms without additional modifications. For the main peak eluting from 39.0 to $41.5 \mathrm{~min}$, the MS data allowed assignment of the same mAb1 glycoforms with a systematic mass difference of +16 Da, which potentially corresponds to the oxidation of one amino acid residue (Figure S-1). Finally, deconvolution of the mass spectra acquired for the first eluting peak (35.5-38.9 min) led to the identification of the same major glycoforms, however, with an additional mass difference of +32 Da suggesting the presence of two oxidations per mAb1. The results are in agreement with a previous study on affinity LC-UV, in which a stepwise decreased FcRn receptor affinity was observed for singly and doubly oxidized mAb1. ${ }^{18}$ Other studies recently reported a similar impact of IgG Met oxidation on IgG Fc-FcRn receptor affinity using different techniques. ${ }^{32,33}$ Results obtained for the analysis of mAb1 suggest that a single oxidation occurring on the peptide backbone is significantly lowering the mAb affinity for the FcRn receptor and an additional oxidation further decreases the affinity.

Several experiments were performed in order to establish whether native FcRn affinity LC-ESI-MS could be extended to other recombinant IgGs. The mAb2 reference formulation was characterized by FcRn affinity LC-ESI-MS. The chromatogram obtained for the analysis of mAb2 showed only one peak with a retention time of 45.9 min (Figure S3). To assess specificity of IgG-FcRn receptor interaction, mAb3 exhibiting abrogated FcRn binding capacity was used as a negative control. ${ }^{24,25}$ The chromatogram obtained for the analysis of mAb3 shows a single peak eluting at 
$2.25 \mathrm{~min}$ which corresponds to the dead volume of the chromatographic system. This result indicates that mAb3 does not interact with the FcRn receptor stationary phase because it is unable to interact with the FcRn receptor (Figure S-4).

Influence of Antibody Glycosylation on FcRn Binding. Similarly to natural IgGs, mAbs produced using recombinant technologies have an $\mathrm{N}$-glycosylation site in the $\mathrm{CH} 2$ domain of each heavy chain. $\mathrm{N}$-Glycosylation contributes substantially to mAbs heterogeneity because of the various glycan structures expressed and the different combinations of glycosylation for each of the two heavy chains constituting the protein. ${ }^{34,35}$

Glycan nature may significantly influence the physicochemical properties and higher-order structure of proteins, which in some cases might involve dramatic modification of the functional properties, as has been reported for the interaction with the Fc $\gamma$ RIIIa receptor. ${ }^{36,37}$ To evaluate the contribution of the Fc N-glycosylation on FcRn receptor binding, native FcRn affinity LC analysis with glycosylated and deglycosylated mAb1 was performed. The chromatograms obtained for the analysis of intact and deglycosylated mAb1 were found to be highly similar with respect to peak distribution and retention times. Both chromatograms exhibited three consecutive peaks with comparable retention times (Figure $\mathrm{S}-5)$. From these results it can be concluded that the Fc N-glycosylation does not significantly affect the affinity with the FcRn receptor or the separation observed in the native FcRn LC-ESI-MS (Figure 1C).

Native FcRn Affinity LC-ESI-MS of mAb Stressed Samples. Native FcRn affinity LC-ESI-MS analysis of oxidized mAb1 demonstrated the separation of three types of variants having significantly different affinity for the FcRn receptor, which based on the obtained MS data could be ascribed to the degree of mAb1 oxidation (Figure 1C). In order to elucidate the amino acid modifications responsible for the decreased affinity, different oxidative stress treatments were applied to mAb2. Oxidation was artificially introduced through incubation with hydrogen peroxide at concentrations ranging from $0 \%$ up to $0.05 \%(\mathrm{v} / \mathrm{v}) .{ }^{38}$ The stressed samples were then analyzed by native FcRn affinity LC-ESI-MS (Figure 3A) and total ion chromatogram signal intensities were used to estimate the relative abundance of the oxidized mAb2 variants (Table 2). The chromatogram obtained for the control sample $\left(0 \% \mathrm{H}_{2} \mathrm{O}_{2}\right)$ showed a single peak with a retention time of $45.9 \mathrm{~min}$. For mAb2 incubated with $0.009 \% \mathrm{H}_{2} \mathrm{O}_{2}$, three peaks eluting at 40.4 , 43.3, and 45.9 min could be obtained (Figure 3A). 

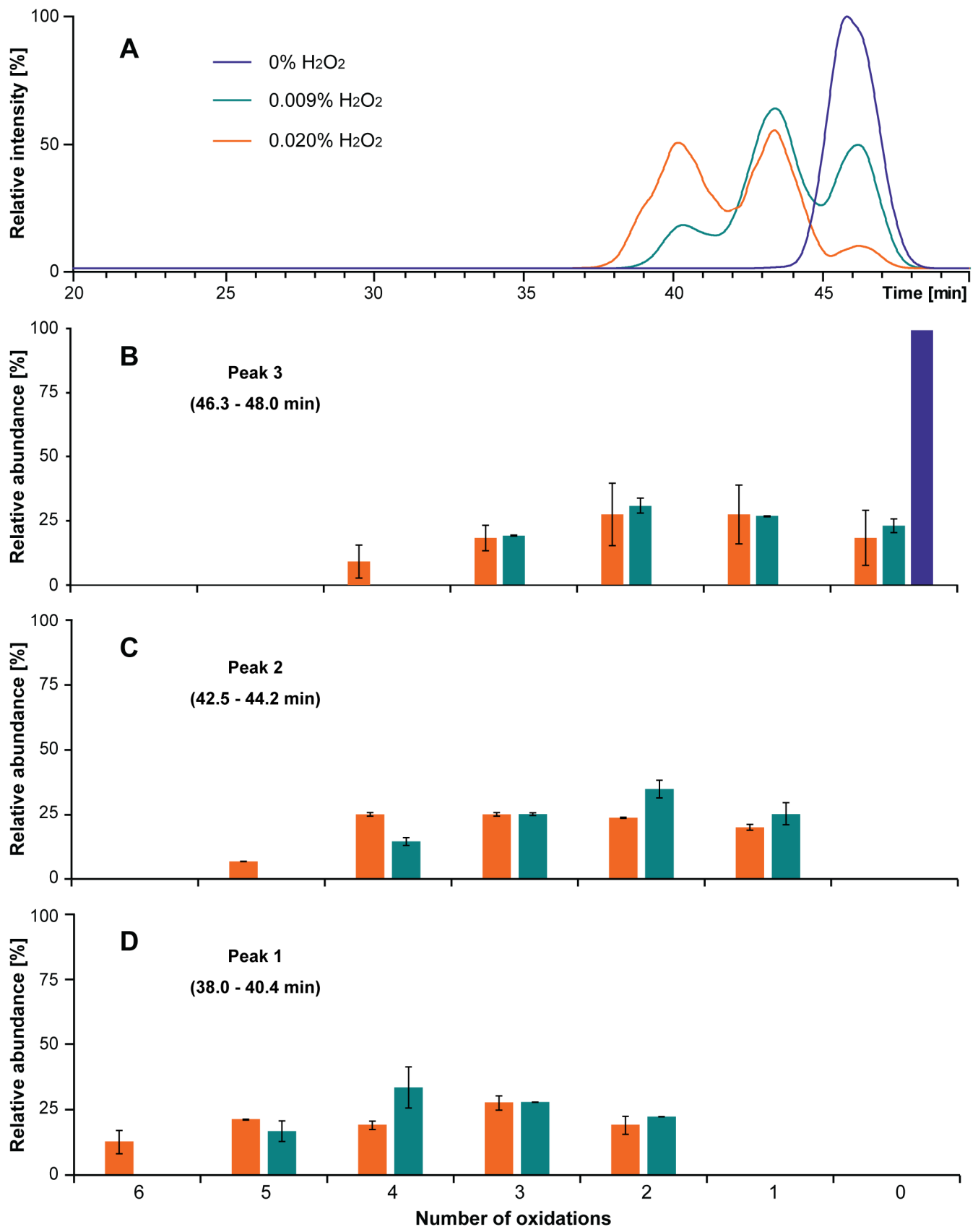

Figure 3. (A) Total ion chromatogram (TIC) recorded during native FcRn LC-ESI-MS of mAb2 incubated for $24 \mathrm{~h}_{\mathrm{Hith}} \mathrm{H}_{2} \mathrm{O}_{2}$ at concentrations ranging from $0 \%$ to $0.02 \%$. Relative abundances of variants observed during native FcRn affinity LC-ESI-MS of mAb2 control sample (blue), after incubation with $0.009 \% \mathrm{H}_{2} \mathrm{O}_{2}$ (green), $0.020 \% \mathrm{H}_{2} \mathrm{O}_{2}$ (orange) for (B) retention window $46.3-48.0$ min (peak 3), (C) retention window 42.5-44.2 min (peak 2), and (D) retention window 38.0-40.4 min (peak 1). Relative abundances were estimated from the native MS signal for the glycoform [H3N4F/H4N4F]; all error bars are referring to the standard deviation of the signal observed for this glycoform (performed in triplicates). 
With the formation of additional species, a concomitant decrease in the relative abundance of the unmodified mAb2 was observed (Table 2). When incubating with $0.020 \% \mathrm{H}_{2} \mathrm{O}_{2}$ (Figure $3 \mathrm{~A}$ ), the relative abundance of the unmodified mAb2 was lower compared to the other variants (Table 2). For the oxidative treatment performed on mAb2 by incubation with $0.05 \% \mathrm{H}_{2} \mathrm{O}_{2}$, a peak corresponding to unmodified mAb2 was not detected anymore, indicating the mAb was totally modified (Table 2). Mass data obtained during native FcRn affinity LC-ESI-MS enabled assignment of the four major glycoforms of mAb2 for each of the separated species.

Table 2. Relative Abundance Corresponding to the Different Species Separated by FcRn Affinity LC-ESI-MS for mAb2 Oxidation Stress Samples ${ }^{\mathrm{a}}$

\begin{tabular}{|l|l|l|l|}
\hline oxidative stress $\left(\% \mathrm{H}_{2} \mathrm{O}_{2}\right)$ & peak 1 & peak 2 & peak 3 \\
\hline 0 & 0 & 0 & 100.00 \\
\hline 0.003 & 0 & 28.13 & 71.87 \\
\hline 0.009 & 13.30 & 48.92 & 37.78 \\
\hline 0.015 & 31.31 & 49.32 & 19.37 \\
\hline 0.020 & 43.86 & 48.21 & 7.93 \\
\hline 0.050 & 81.01 & 18.99 & 0 \\
\hline
\end{tabular}

aValues were obtained using the absolute abundance of each chromatographic peak and average on experiments performed in triplicates.

The MS signal intensities corresponding to the various oxidized species were used to assess the effect of the hydrogen peroxide treatment on the FcRn affinity. The last peak eluting at 45.9 min allowed the identification of mAb2 with a number of oxidations between 0 and 4 (Figure 3B). Therefore, the unmodified mAb2 could be identified only at this retention time. This observation supports the conclusion that oxidation is not strictly inducing a reduction of FcRn receptor affinity. The second peak at 43.3 min allowed the identification of the same glycoforms with $1-5$ oxidations (Figure 3C). The variability of the number of oxidations detected for a single retention time also points that the oxidation of various sites is not necessarily impacting mAb2 FcRn receptor affinity. The first peak is observed at $40.3 \mathrm{~min}$ for concentration of hydrogen peroxide equal or above $0.009 \%$. Considering the identified species, MS data revealed mAb2 exhibiting a number of oxidations from 2 up to 6 as emphasized in Figure 3D. The variants identified for this 
particular peak have at least two oxidations, which is explained by the harsh oxidative conditions applied to the sample. Native FcRn affinity LC-ESI-MS data showed for the separated peaks similar glycoform distributions which is in agreement with the concept that Fc N-glycosylation has hardly any influence on the interaction with the FcRn receptor and is not responsible for the observed separation.

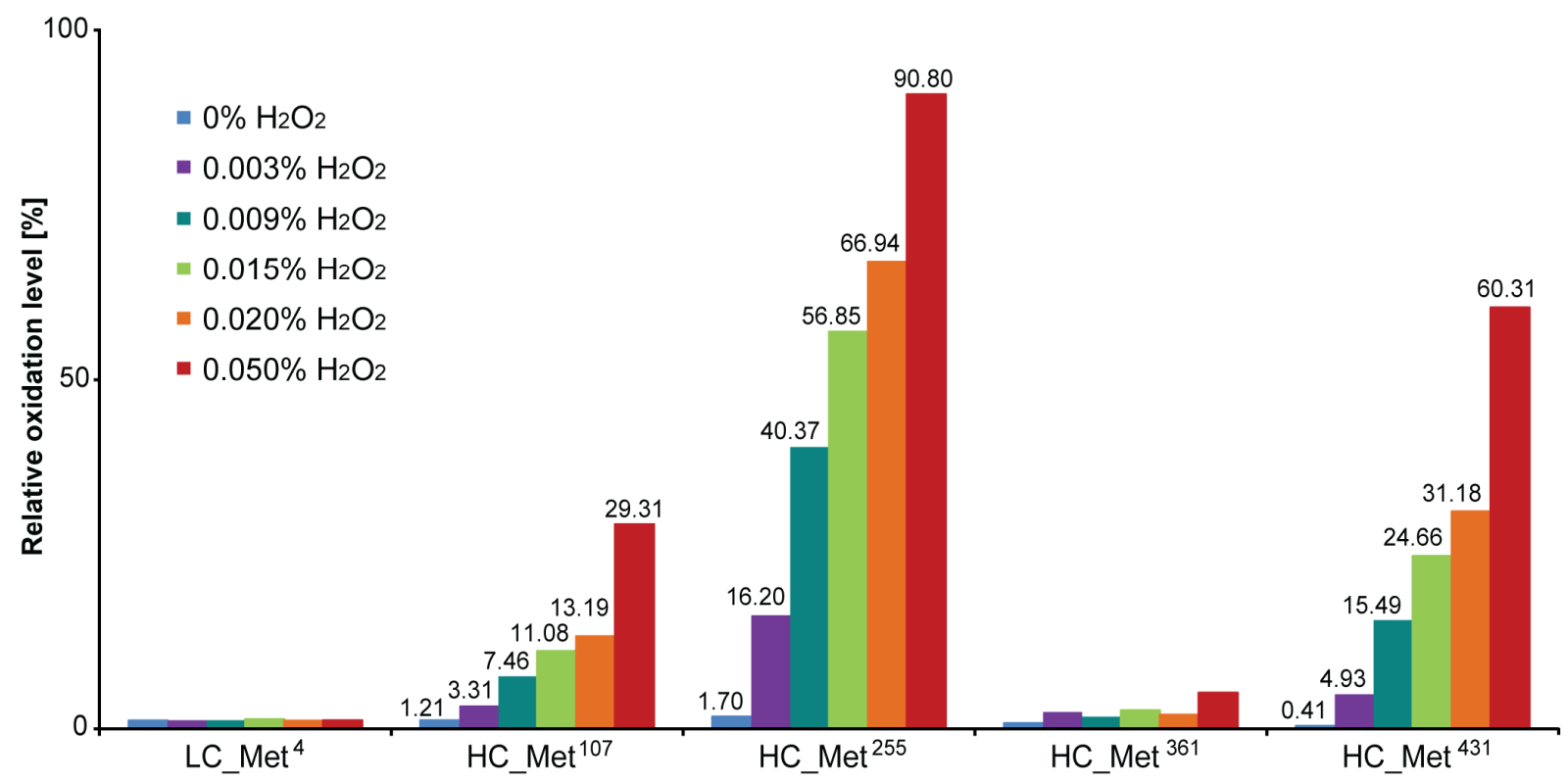

Figure 4. Relative oxidation levels for mAb2 methionine residues depending of the oxidative stress conditions applied. Oxidation levels were established from the analysis of the tryptic digests using RPLC-ESI-MS/MS (cf. the Experimental Section).

For further localization of the amino acid oxidations, each stressed sample was digested using trypsin and the peptide mixtures generated were analyzed by RPLC-ESI-MS/MS. These experiments also allowed determination of the respective oxidation levels depending on the stress conditions applied. Figure 4 compiles the relative modification levels estimated for the different methionine (Met) residues present on the mAb2 peptide backbone. Results show that oxidative stress conditions did not affect residues Met4 on the light chain and Met83 (data not shown) on the heavy chain. This can be explained because those two amino acids are buried deeply in the quaternary structure and are less accessible to the solvent. ${ }^{39}$ Similarly, Met361 is weakly affected regardless of the oxidative stress conditions applied. However, native FcRn affinity LC-ESI-MS chromatograms show the formation of oxidized variants, because the concentration of $\mathrm{H} 2 \mathrm{O} 2$ used for the pretreatment is increased, until the complete modification of the reference mAb2 (Table 
2). It could be concluded the oxidation of Met361 is not related to a decrease in the FcRn receptor affinity, responsible for the chromatographic separation observed in native FcRn affinity LC-ESI-MS (Figure 1C). The level of oxidation estimated for heavy-chain Met107 residue is gradually increased as the concentration of $\mathrm{H}_{2} \mathrm{O}_{2}$ is higher (Figure 4). Met107 is part of the Fab fragment; therefore, it is not interacting directly with the FcRn receptor. The oxidation levels determined from the tryptic digest analysis (Figure 4) did not show any correlation with the relative abundances for the analysis of mAb2 stressed sample by FcRn affinity LC-ESI-MS. Especially, the chromatogram obtained for incubation with $0.05 \% \mathrm{H}_{2} \mathrm{O}_{2}$ does not enable the detection of unmodified mAb2 (Table 2). However, Met107 oxidation level reaches only $29.31 \%$ for the harshest oxidative treatment, which should enable the detection of mAb2 without oxidation (Figure 4).

Met431 is located in the $\mathrm{CH} 3$ portion of IgG Fc part; as a consequence, the modification of this residue may have an influence on the affinity for receptors interacting with the Fc fragment which includes the FcRn receptor. Estimations of the oxidation levels depending on the stress applied demonstrate for Met431 significant modification levels ranging from $4.9 \%$ for $\mathrm{mAb} 2$ treated using $0.003 \% \mathrm{H}_{2} \mathrm{O}_{2}$ up to $60.3 \%$ in the case of an oxidative treatment using $0.05 \% \mathrm{H}_{2} \mathrm{O}_{2}$ (Figure 4). The highest oxidation level estimated from tryptic digest analysis should still enable the detection of the unmodified mAb2 with an optimal sensitivity even for an oxidative treatment with $0.05 \% \mathrm{H}_{2} \mathrm{O}_{2}$. However, native FcRn affinity LC-ESI-MS experiments did not allow the identification of unmodified mAb2 for this stressed sample. Nevertheless, no correlation could be established between the oxidation levels of Met431 determined from the tryptic digest analysis and the oxidation levels estimated from FcRn LC-ESI-MS chromatograms (Table 2). The experiments allowed us to conclude that Met431 is undergoing significant oxidation due to extensive exposition to $\mathrm{H}_{2} \mathrm{O}_{2}$, although the oxidation of this amino acid is not responsible for significant affinity changes; indeed, this conclusion is in agreement with the literature. ${ }^{18}$

Heavy-chain Met255 is located in the $\mathrm{CH} 2$ domain of IgGs. ${ }^{14}$ Results obtained from the tryptic digest analysis show a gradual increase of the oxidation level of Met255, whereas the concentration of $\mathrm{H}_{2} \mathrm{O}_{2}$ is higher with a maximum value of $90.8 \%$ for an incubation with $0.05 \% \mathrm{H} 2 \mathrm{O} 2$ (Figure 4). Because mAbs are incorporating two identical heavy chains, 
the protein can exhibit 0,1 , or 2 oxidations for the same position. For each stressed sample, absolute intensities determined from FcRn affinity LC-ESI-MS experiments were used to deduce the proportion of modified Met255 considering that the first peak (35.5-38.9 min) would contribute twice more because of the oxidation of both heavy chains compared to the second eluting peak (39.1-41.4 $\mathrm{min}$ ) constituted of the mAbs with only one modified heavy chain using the following formula:

$$
\text { oxidation level }(\%)=\frac{\left(2 I_{\text {peak1 } 1}\right)+I_{\text {peak2 }}}{2 \sum\left(I_{\text {peak } 1 \rightarrow 3}\right)} \times 100
$$

where I represents the TIC absolute intensity of the chromatographic peak. Results obtained using this formula for the various stressed samples were directly confronted to the oxidation levels determined for Met255 on the peptide level using peptide mapping experiments (Figure 4). Met255 oxidation levels determined from tryptic digest analysis and native FcRn affinity LC-ESI-MS data using eq 1 were in complete agreement for the different oxidative treatment applied (Figure 5). Native MS identifications supported by the comparison with the oxidation level allowed us to conclude that oxidation of Met255 residue is responsible for the separation in FcRn affinity chromatography. Results obtained support the conclusion that the decrease of FcRn affinity, expressed by a reduction of the retention time, is due to the oxidation of a particular amino acid. As a consequence the oxidation of both sites present on each chain of the $\mathrm{mAb}$ is reducing even further the FcRn receptor affinity (Table S-1). This conclusion is also in agreement with the results recently described by Stracke et al. ${ }^{18}$

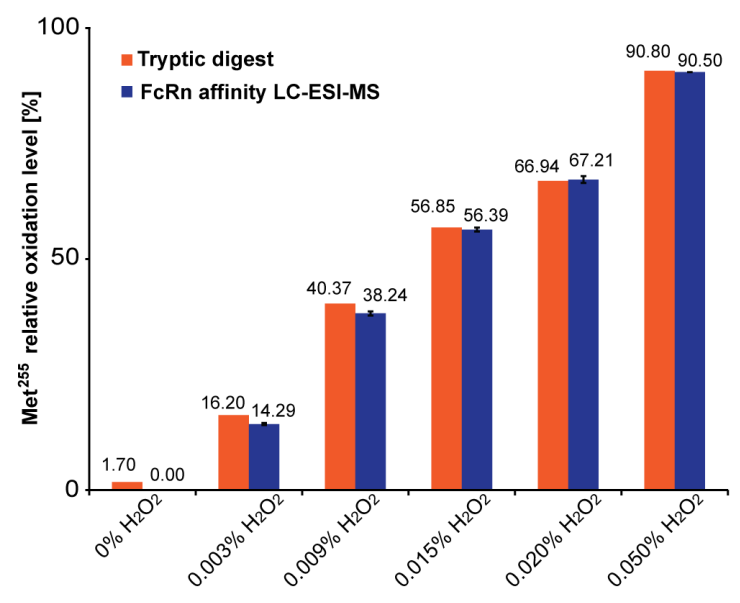

Figure 5. Comparison of the oxidation levels for Hc Met255 for the different oxidative treatments applied estimated independently from the tryptic digest analysis (orange bars) and native FcRn affinity LC-ESI-MS (blue bars) analysis (performed in triplicates). Error bars are referring to standard deviation. 
On the basis of the described experiments, it is possible to conclude that variants eluting with shorter retention times in native FcRn affinity LC-ESI-MS demonstrate lowered affinities with FcRn receptor. The variants eluting first are corresponding to the mAbs variants having both Met255 amino acids oxidized. For the second eluting peak, the species identified corresponds to mAb2 with oxidation occurring solely on one heavy chain. The final peak exhibits the optimal affinity with the FcRn receptor; species identified were attributed to the mAbs variants free from Met255 residues oxidation. Various species with more than two oxidations could be identified due to the harsh oxidative conditions applied to the sample which in the case of $0.050 \% \mathrm{H}_{2} \mathrm{O}_{2}$ increases significantly the oxidations levels of other amino acids like Met107 and Met431. The conditions led to the identification of variants oxidized on different hotspots. However, mass spectra assignment for the first eluting peak could not show the identification of species exhibiting only a single oxidation for this experiment. This observation demonstrates that the lowest affinity with the FcRn receptor is the consequence of the oxidation of the two amino acid residues present on each heavy chains. The amino acid Met255 is part of the Fc fragment and is common to numerous types of human antibodies, typically on position Met 25X depending on the Fab fragment amino acid sequence. The oxidation of this particular amino acid has been described to reduce the affinity of IgGs for the FcRn receptor using other techniques. ${ }^{40,41}$

\section{CONCLUSION}

Native FcRn affinity LC-ESI-MS implementing a stationary phase composed of immobilized neonatal FcRn receptor could be used for the characterization of therapeutic mAbs. Extensive optimization of the conditions was conducted in order to be compatible with native ESI-MS in concomitance to enable the smooth $\mathrm{pH}$ change essential to the separation of mAbs variants with significantly different affinities with the FcRn receptor. The experiments demonstrated the separation and independent assignment based on MS data of mAbs variants demonstrating different FcRn receptor affinities. Native FcRn affinity LC-ESIMS data provided satisfying mass accuracies, which enabled systematic identification of the major glycoforms. Thus, results achieved enabled correlation of oxidations with FcRn receptor affinity decrease. To precisely localize the modification responsible for the reduction of FcRn receptor affinity, oxidative stresses were applied to a therapeutic mAb using different conditions and analyzed by native FcRn affinity LC-ESI- 
MS. Identifications obtained from native FcRn affinity LC-ESI-MS results demonstrated that $\mathrm{H} 2 \mathrm{O} 2$ incubation implies the oxidation of various Met residues present on the peptide backbone of the studied mAb but also suggested the oxidation of a specific residue is responsible for the affinity change. Comparison of the oxidation level determined independently from tryptic digest analysis and native FcRn affinity LC-ESI-MS data was in complete agreement in the case of Met255 showing this particular oxidation is responsible for the reduction of FcRn receptor affinity observed. Native FcRn affinity LC-ESI-MS data enabled the determination of the relative abundance of mAb2 oxidized variants generated during $\mathrm{H} 2 \mathrm{O} 2$ incubation, which gives a different insight of the studied sample.

The developed method demonstrates an alternative way of studying this important interaction by the intermediate of FcRn affinity LC completed with the detailed identifications provided by native MS analysis. Results are presenting an analytical methodology to correlate FcRn affinity changes with modifications of the primary structure of the studied $\mathrm{mAb}$ in a reduced number of experiments, which may be particularly valuable from a research and development perspective. In addition, the comparison with the data collected from the tryptic digest analysis enabled us to specifically localize the oxidation responsible for the affinity changes and demonstrated that native FcRn affinity LC-ESI-MS analysis provides accurate information regarding the degree of modification of the sample. Native FcRn affinity LC-ESI-MS revealed the attractive aspects of analysis in native conditions because it is essential to mimic correctly IgG-FcRn receptor interactions. In the future, native affinity LC-ESI-MS could be applied to study other therapeutic IgGs functions such as effector function with the implementation of stationary phases incorporating other types of receptors. The successful coupling of FcRn affinity LC and ESI-MS in native conditions suggests that native MS could benefit greatly from the implementation of compatible separations in order to diversify the applicability and extend the interest of native MS analysis especially to characterize more complex samples.

\section{ASSOCIATED CONTENT}

The Supporting Information is available free of charge on the ACS Publications website at DOI: 10.1021/acs.analchem. $7 \mathrm{~b} 00211$. 


\section{ACKNOWLEDGMENTS}

R.G. received funding for salary and consumables from Roche Diagnostics GmbH on the basis of the research agreement "Native protein separation combined with native protein mass spectrometry for protein characterization" between Vrije Universiteit Amsterdam and Roche Diagnostics (February 2015).

\section{REFERENCES}

(1) Beck, A.; Wurch, T.; Bailly, C.; Corvaia, N. Nat. Rev. Immunol. 2010, 10, 345-352.

(2) Liu, H.; Gaza-Bulseco, G.; Faldu, D.; Chumsae, C.; Sun, J. J. Pharm. Sci. 2008, 97, 2426-2447.

(3) Said, N.; Gahoual, R.; Kuhn, L.; Beck, A.; François, Y.-N.; Leize-Wagner, E. Anal. Chim. Acta 2016, 918, 50-59.

(4) Haberger, M.; Leiss, M.; Heidenreich, A.-K.; Pester, O.; Hafenmair, G.; Hook, M.; Bonnington, L.; Wegele, H.; Haindl, M.; Reusch, D.; Bulau, P. mAbs 2016, 8, 331-339.

(5) Fekete, S.; Guillarme, D.; Sandra, P.; Sandra, K. Anal. Chem. 2016, 88, 480-507.

(6) McKay, A. R.; Ruotolo, B. T.; Ilag, L. L.; Robinson, C. V. J. Am. Chem. Soc. 2006, 128, $11433-11442$.

(7) Gahoual, R.; Busnel, J.-M.; Wolff, P.; François, Y. N.; Leize-Wagner, E. Anal. Bioanal. Chem. 2014, 406, 1029-1038.

(8) Hao, P.; Ren, Y.; Datta, A.; Tam, J. P.; Sze, S. K. J. Proteome Res. 2015, 14, 1308-1314.

(9) Debaene, F.; Boeuf, A.; Wagner-Rousset, E.; Colas, O.; Ayoub, D.; Corvaïa, N.; Van Dorsselaer, A.; Beck, A.; Cianférani, S. Anal. Chem. 2014, 86, 10674-10683.

(10) Haberger, M.; Heidenreich, A.-K.; Schlothauer, T.; Hook, M.; Gassner, J.; Bomans, K.; Yegres, M.; Zwick, A.; Zimmermann, B.; Wegele, H.; Bonnington, L.; Reusch, D.; Bulau, P. mAbs 2015, 7, 891-900.

(11) Atmanene, C.; Wagner-Rousset, E.; Malissard, M.; Chol, B.; Robert, A.; Corvaïa, N.; Dorsselaer, A. V.; Beck, A.; Sanglier-Cianférani, S. Anal. Chem. 2009, 81, 6364-6373.

(12) Debaene, F.; Wagner-Rousset, E.; Colas, O.; Ayoub, D.; Corvaïa, N.; Van Dorsselaer, A.; Beck, A.; Cianférani, S. Anal. Chem. 2013, 85, 9785-9792.

(13) Diepold, K.; Bomans, K.; Wiedmann, M.; Zimmermann, B.; Petzold, A.; Schlothauer, T.; Mueller, R.; Moritz, B.; Stracke, J. O.; Mølhøj, M.; Reusch, D.; Bulau, P. PLoS One 2012, 7, e30295.

(14) Gahoual, R.; Busnel, J.-M.; Beck, A.; François, Y.-N.; Leize-Wagner, E. Anal. Chem. 2014, 86, 9074-9081. 
(15) Grodzki, A. C.; Berenstein, E. In Immunocytochemical Methods and Protocols; Oliver, C., Jamur, M. C., Eds.; Humana Press: Totowa, NJ, 2010; pp 33-41.

(16) Hober, S.; Nord, K.; Linhult, M. J. Chromatogr. B: Anal. Technol. Biomed. Life Sci. 2007, 848, 40-47.

(17) Schlothauer, T.; Rueger, P.; Stracke, J. O.; Hertenberger, H.; Fingas, F.; Kling, L.; Emrich, T.; Drabner, G.; Seeber, S.; Auer, J.; Koch, S.; Papadimitriou, A. mAbs 2013, 5, 576-586.

(18) Stracke, J.; Emrich, T.; Rueger, P.; Schlothauer, T.; Kling, L.; Knaupp, A.; Hertenberger, H.; Wolfert, A.; Spick, C.; Lau, W.; Drabner, G.; Reiff, U.; Koll, H.; Papadimitriou, A. mAbs 2014, 6, 1229-1242.

(19) Leach, J. L.; Sedmak, D. D.; Osborne, J. M.; Rahill, B.; Lairmore, M. D.; Anderson, C. L. J. Immunol. 1996, 157, 3317-3322.

(20) Ward, E. S.; Zhou, J.; Ghetie, V.; Ober, R. J. Int. Immunol. 2003, 15, 187-195.

(21) Roopenian, D. C.; Akilesh, S. Nat. Rev. Immunol. 2007, 7, 715-725.

(22) Kontermann, R. E. Curr. Opin. Biotechnol. 2011, 22, 868-876.

(23) Ferrara, C.; Brünker, P.; Suter, T.; Moser, S.; Püntener, U.; Umaña, P. Biotechnol. Bioeng. 2006, 93, $851-861$.

(24) Schaefer, W.; Regula, J. T.; Bähner, M.; Schanzer, J.; Croasdale, R.; Dürr, H.; Gassner, C.; Georges, G.; Kettenberger, H.; Imhof-Jung, S.; Schwaiger, M.; Stubenrauch, K. G.; Sustmann, C.; Thomas, M.; Scheuer, W.; Klein, C. Proc. Natl. Acad. Sci. U. S. A. 2011, 108, 11187-11192.

(25) Klein, C.; Sustmann, C.; Thomas, M.; Stubenrauch, K.; Croasdale, R.; Schanzer, J.; Brinkmann, U.; Kettenberger, H.; Regula, J. T.; Schaefer, W. mAbs 2012, 4, 653-663.

(26) Wang, G.; de Jong, R. N.; van den Bremer, E. T. J.; Beurskens, F. J.; Labrijn, A. F.; Ugurlar, D.; Gros, P.; Schuurman, J.; Parren, Paul W. H. I.; Heck, Albert J. R. Mol. Cell 2016, 63, 135-145.

(27) de Jong, R. N.; Beurskens, F. J.; Verploegen, S.; Strumane, K.; van Kampen, M. D.; Voorhorst, M.; Horstman, W.; Engelberts, P. J.; Oostindie, S. C.; Wang, G.; Heck, A. J. R.; Schuurman, J.; Parren, P. W. H. I. PLoS Biol. 2016, 14, e1002344.

(28) Vaccaro, C.; Zhou, J.; Ober, R. J.; Ward, E. S. Nat. Biotechnol. 2005, 23, 1283-1288.

(29) Heck, A. J. R. Nat. Methods 2008, 5, 927-933.

(30) Sterling, H. J.; Batchelor, J. D.; Wemmer, D. E.; Williams, E. R. J. Am. Soc. Mass Spectrom. 2010, 21, 1045-1049.

(31) Thompson, N. J.; Rosati, S.; Heck, A. J. R. Methods 2014, 65, 11-17.

(32) Tsuchida, D.; Yamazaki, K.; Akashi, S. Pharm. Res. 2016, 33, 994-1002.

(33) Mo, J.; Yan, Q.; So, C. K.; Soden, T.; Lewis, M. J.; Hu, P. Anal. Chem. 2016, 88, 9495-9502. 
(34) Reusch, D.; Tejada, M. L. Glycobiology 2015, 25, 1325-1334.

(35) Dotz, V.; Haselberg, R.; Shubhakar, A.; Kozak, R. P.; Falck, D.; Rombouts, Y.; Reusch, D.; Somsen, G. W.; Fernandes, D. L.; Wuhrer, M. TrAC, Trends Anal. Chem. 2015, 73, 1-9.

(36) Krapp, S.; Mimura, Y.; Jefferis, R.; Huber, R.; Sondermann, P. J. Mol. Biol. 2003, 325, 979-989.

(37) Raju, T. S. Curr. Opin. Immunol. 2008, 20, 471-478.

(38) Haberger, M.; Bomans, K.; Diepold, K.; Hook, M.; Gassner, J.; Schlothauer, T.; Zwick, A.; Spick, C.; Kepert, J. F.; Hienz, B.; Wiedmann, M.; Beck, H.; Metzger, P.; Mølhøj, M.; Knoblich, C.; Grauschopf, U.; Reusch, D.; Bulau, P. mAbs 2014, 6, 327-339.

(39) Shen, F. J.; Kwong, M. Y.; Keck, R. G.; Harris, R. J. In Techniques in Protein Chemistry; Daniel, R. M., Ed.; Academic Press: San Diego, CA, 1996; pp 275-284.

(40) Liu, D.; Ren, D.; Huang, H.; Dankberg, J.; Rosenfeld, R.; Cocco, M. J.; Li, L.; Brems, D. N.; Remmele, R. L. Biochemistry 2008, 47, 5088-5100.

(41) Bertolotti-Ciarlet, A.; Wang, W.; Lownes, R.; Pristatsky, P.; Fang, Y.; McKelvey, T.; Li, Y.; Li, Y.; Drummond, J.; Prueksaritanont, T.; Vlasak, J. Mol. Immunol. 2009, 46, 1878-1882. 